\title{
A Progestin-Based Treatment with a High Dose of Estradiol Benzoate Normalizes Cyclic Changes in Endometrial EGF Concentrations and Restores Fertility in Repeat Breeder Cows
}

\author{
Seiji KATAGIRI ${ }^{1)}$ and Yoshiyuki TAKAHASHI ${ }^{1)}$ \\ 1) Laboratory of Theriogenology, Department of Veterinary Clinical Sciences, Graduate School of Veterinary Medicine, \\ Hokkaido University, Sapporo 060-0818, Japan
}

\begin{abstract}
The objective of the present study was to examine the efficacy of a progestin-based treatment with a high dose of estradiol benzoate (EB) to normalize the epidermal growth factor (EGF) profile in the uterine endometrium and restore fertility in repeat breeder cows. Repeat breeder cows without peaks in their endometrial EGF concentrations on Days 3 and 14 of the estrous cycle were used throughout the study. The effect of 1 (standard dose), 2.5 and $5 \mathrm{mg}$ of EB in a progestin-based treatment protocol (EB1, EB2.5 and EB5 treatments, respectively; $n=5$ for each group) on endometrial EGF concentrations was first examined. The EB1 and EB2.5 treatments in the repeat breeder cows produced a suppressed response in endometrial EGF compared with EB1 treatment in the fertile controls $(n=5)$ and failed to restore the normal EGF profile during the next estrous cycle. However, EB5 treatment produced an increase in EGF concentrations similar to the fertile controls and normalized the endometrial EGF profile. The effects of the EB1 and EB5 treatments ( $\mathrm{n}=30$ for each group) on the endometrial EGF profile and fertility were then examined in the repeat breeder cows. The proportion of cows, with an EGF profile normalized by the treatments was higher in the EB5 group $(66.7 \%)$ than in the EB1 $(30.0 \%)$ and untreated control $(13.3 \% ; n=30)$ groups $(\mathrm{P}<0.01)$. The pregnancy rates of the cows having a normal EGF profile after treatment in the EB1 and EB5 groups were similar (88.9 and 85.0\%, respectively) and higher than those of the cows having an abnormal profile within the same groups (19.0 and $30.0 \%$, respectively, $\mathrm{P}<0.01)$. In summary, the endometrial response to EB in terms of the EGF concentration was suppressed in repeat breeder cows. A high dose $(5 \mathrm{mg})$ of EB in a progestin-based treatment was found to be effective for restoration of a normal EGF profile and fertility in repeat breeder cows having lesser endometrial EGF concentrations on Days 3 and 14.
\end{abstract}

Key words: Controlled intravaginal drug release (CIDR), Dairy cattle, Epidermal growth factor (EGF), Endometrium, Repeat breeding

(J. Reprod. Dev. 54: 473-479, 2008)

G rowing evidence indicates that ovarian steroid hormones (i.e., estrogen and progestin) primarily regulate uterine function by stimulating uterine production of growth factors and cytokines, although most of our knowledge in this field has been obtained in mice and rats. Among such local products, epidermal growth factor (EGF) and related ligands that share the EGF receptor have critical functions in the establishment of pregnancy [1, 2]. Estrogen stimulates EGF production in the mouse uterus [3-5] and human oviducts [6]. Epidermal growth factor replaces estrogen in the stimulation of uterine and vaginal growth and endometrial cell differentiation (e.g., induction of lactoferrin, a major estrogeninducible secretory protein) in mice [7] and in a nidatory estrogen surge that initiates blastocyst attachment to the endometrium in rats [8]. In EGF receptor knockout mice, drastic negative effects on the number of inner cell masses [9], placenta formation and viability of offspring $[9,10]$ have been reported. The presence of EGF and its receptor in the endometrium have been reported in many farm species, including cattle [11-13], sheep [14, 15], goats [16] and pigs [17]. Furthermore, EGF increases endometrial production of prostaglandin $(\mathrm{PG}) \mathrm{E}_{2}$ and the $\mathrm{PGE}_{2}: \mathrm{PGF}_{2 \alpha}$ ratio in pigs [18] and rats

Accepted for publication: September 4, 2008

Published online in J-STAGE: October 15, 2008

Correspondence: S Katagiri (e-mail: katagiri@vetmed.hokudai.ac.jp)
[19]. These effects of EGF on endometrial PG production should enhance CL function in the cattle [20, 21].

Recently, we have reported the presence of repeat breeder cows that exhibit an abnormality in the profile of their uterine endometrial EGF concentrations [11]. Cyclic cows had two peaks in their endometrial EGF concentrations on Days 2-4 and 13-14 of the estrous cycle; however, these two peaks were not detected in the repeat breeder cows. The abovementioned potential roles of EGF in establishment of pregnancy in cattle suggest that the abnormality in the EGF profile may be one of the causes of infertility in repeat breeder cows [11]. Accordingly, our recent study suggested a potential relationship between normalization of the EGF profile and restoration of fertility in repeat breeder cows [22]. Since the incidence of abnormal EGF profile in repeat breeder cows can be as high as 70\% [22], treatment that restores a normal EGF profile would have a major economic impact on the dairy industry.

In the present study, we hypothesized that the uterine endometrial capacity to produce EGF in response to estradiol is suppressed in repeat breeder cows having an abnormal endometrial EGF profile. Since expression of EGF in the endometrium is stimulated by estrogen in the presence of progesterone [1, 2], a progestin-based treatment in combination with a high dose of estradiol may be an effective way to restore the endometrial EGF profile and fertility in this type of repeat breeder cow. In the present study, repeat breeder 
cows were given different doses of estradiol benzoate (EB) in combination with a controlled intravaginal drug release (CIDR) device (CIDR treatment), and the changes in the endometrial EGF concentrations were monitored to determine an effective dose to normalize the endometrial EGF profile in repeat breeder cows (Experiment 1). The effect of the CIDR treatment with standard (1 mg) and high ( $5 \mathrm{mg}$ ) doses of EB on restoration of the endometrial EGF profile and fertility was then compared in a farm setting (Experiment 2).

\section{Materials and Methods}

\section{Animals}

Cows diagnosed as repeat breeders by local practitioners were recruited for the present study using the criteria of failing to conceive after three or more AIs without a detectable abnormality in clinical signs, the estrous cycle and genital organs. The cows were then confirmed to meet the definition of repeat breeders with additional examinations that included transrectal ultrasonography of the genital tracts, uterine cytology for endometritis and oviductal patency by one of the authors before enrollment. The repeat breeder cows were multiparous lactating Holstein cows $(10,500 \mathrm{~kg}$, 305-days FCM on average) between three and nine years of age and between 145 and 250 days post-partum on the day of the first biopsy. All cows had not been given any therapeutic treatment against repeat breeding, including hormonal treatment to induce and/or synchronize estrus and ovulation. In Experiment 1, multiparous lactating Holstein cows with no peripartum problems, between three and six years of age and between 70 and 90 days post-partum on the day of the first biopsy were recruited as fertile cows.

\section{Endometrial tissue collection}

Uterine endometrial tissues were obtained by biopsy using an biopsy instrument (Fujihira Industry, Tokyo, Japan) with caudal epidural anesthesia (4-5 ml of $2 \%$ lidocaine; $2 \%$ xylocaine, Fujisawa Pharmaceutical, Osaka, Japan) as described previously [11]. For the EGF assay, tissues were frozen in liquid nitrogen (within 10 min of collection) and stored at -80 C. For histological examination, endometrial tissues were fixed and preserved in $10 \%$ formalin for at least $48 \mathrm{~h}$. Fixed tissues were embedded in paraffinwax and sectioned at a thickness of $5 \mu \mathrm{m}$. The sections were stained with hematoxylin and eosin.

\section{EGF assay}

Uterine endometrial tissue was processed for the EGF assay as described previously [23] with a modification to increase the ratio of extraction solution (ml) : tissue (g) from 5:1 to 15:1. The concentrations of EGF in uterine extracts were determined by a double-antibody sandwich EIA using 96-well microtiter plates [11]. Anti-human EGF mouse monoclonal antibody (R\&D Systems, Minneapolis, MN, USA) was used as the solid-phase antibody, and anti-human EGF rabbit antiserum (Biogenesis, Poole, UK) was used for detection with anti-rabbit IgG goat antibody (Seikagaku Corporation, Tokyo, Japan) labeled with peroxidase. The intra- and interassay coefficients of variation were 5.6 and $7.4 \%$, respectively. The sensitivity of the assay was $10 \mathrm{pg} /$ well.

\section{Classification of endometrial EGF profiles}

Cows were observed for estrus (the first day of standing estrus= Day 0) twice daily, and two pieces of endometrial tissue were obtained by biopsy on Days 3, 7 and 14 of the estrous cycle. One piece of endometrial tissue on every examination day was used for histological examination to exclude cows with endometritis, and the other was used for the EGF assay. The profiles of endometrial EGF concentrations were judged to be normal when the concentrations on all three days were within the normal range [22], and profiles were judged to be abnormal when the endometrial EGF concentrations were outside the normal range on at least one of the three days. All repeat breeder cows, however, showed EGF concentrations within the normal range on Day 7 of the estrous cycle, and no cows showed EGF concentrations higher than normal on any of the three days in the present study. Therefore, abnormal EGF profiles were characterized by suppressed concentrations on Days 3 and/or 14 of the estrous cycle.

\section{Experiment 1}

A diagrammatic time line of the treatment sequences for Experiment 1 is shown in Fig. $1 \mathrm{~A}$. The changes in the EGF concentrations in response to different doses of EB were examined in repeat breeder cows with an abnormal EGF profile. All cows received a CIDR device containing $1.9 \mathrm{~g}$ of progesterone (EAZIBREED CIDR; InterAg, Hamilton, NZ) on either Day 7, 8 or 9 of the estrous cycle following initial examination of the endometrial EGF profile. The device was left in place for 7 days. Different doses of EB (Gynandol; Sankyo, Tokyo, Japan) and $500 \mu \mathrm{g}$ of cloprostenol (Estrumate; Takeda Schering-Plough Animal Health, Osaka, Japan) were given at the time of insertion and withdrawal of the CIDR device, respectively [24]. Fifteen repeat breeder cows having an abnormal EGF profile were assigned randomly to the three treatment groups that received 1, 2.5 and $5 \mathrm{mg}$ of EB (EB1, EB2.5 and EB5 groups, respectively; five cows for each group) at the time of insertion of the CIDR device. As controls, five fertile cows were similarly treated with $1 \mathrm{mg}$ of EB with a CIDR device (fertile group). Endometrial tissues for EGF assay were obtained by repeated biopsy at $0,2,8,16,24$ and $48 \mathrm{~h}$ after injection of EB and on Days 3, 7 and 14 of the estrous cycle beginning at the estrus observed after withdrawal of the CIDR device. The cows in the control group were subjected to AI up to two times during the next two estrous cycles. Pregnancy was diagnosed by palpation per rectum between Day 60 and Day 65.

\section{Experiment 2}

A diagrammatic time line of the treatment sequences for Experiment 2 is shown in Fig. 1B. The effects of EB treatments with standard (1 mg) and high (5 mg) doses in combination with the CIDR device on normalization of the endometrial EGF profile and fertility were examined in repeat breeder cows having abnormal EGF profiles. Ninety repeat breeder cows showing abnormal EGF profiles were allocated randomly to three treatment groups (thirty cows in each group). The groups consisted of two EB treatment groups (EB1 and EB5 from Experiment 1) and an untreated control 


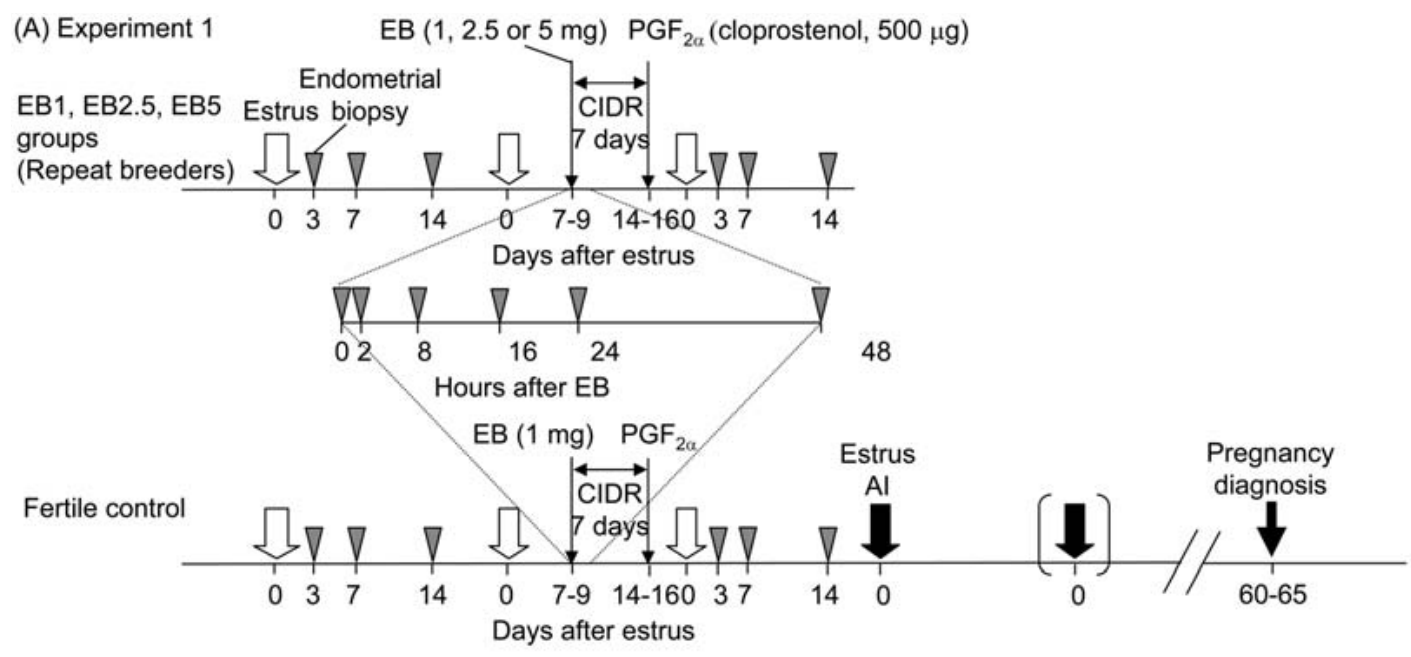

(B) Experiment $2 \quad \mathrm{~EB}(1 \mathrm{or} 5 \mathrm{mg}) \quad \mathrm{PGF}_{2 \alpha}$ (dinoprost, $25 \mathrm{mg}$ )

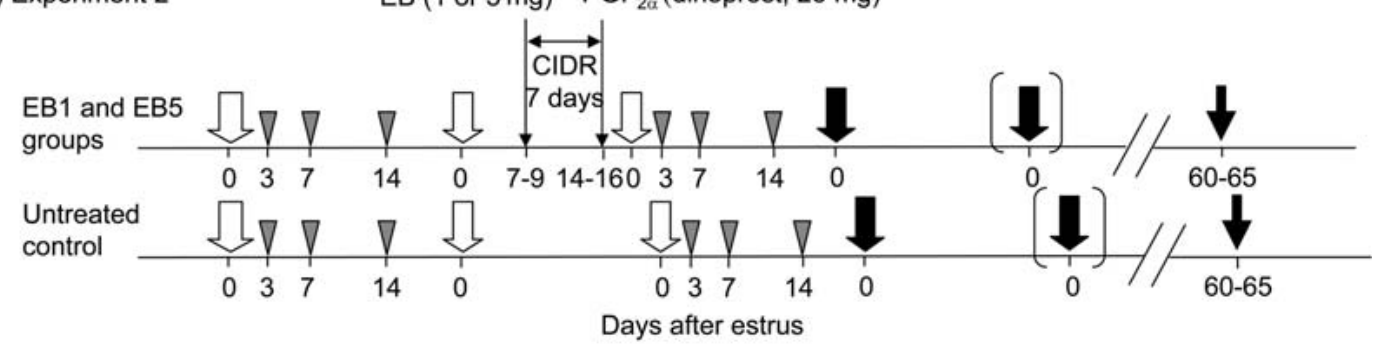

Fig. 1. A diagrammatic time line of the treatment sequences for Experiments 1 and 2 (A and B, respectively). In all cows recruited for the present study, endometrial tissues were obtained for the EGF assay by biopsy on Days 3, 7 and 14 of the estrous cycle (Day 0=estrus). The EGF profile was judged to be abnormal when the endometrial EGF concentrations were outside the normal range on at least one of the three days. In Experiment 1 (A), repeat breeder cows having abnormal endometrial EGF profiles were treated with 1, 2.5 or $5 \mathrm{mg}$ of estradiol benzoate (EB; EB1, EB2.5 and EB5 treatments; $n=5$ for each group) and prostaglandin (PG) $\mathrm{F}_{2 \alpha}$ analogue (500 $\mu$ g of cloprostenol) at the time of insertion (between Day 7 and Day 9 of the estrous cycle) and withdrawal of a controlled internal drug release (CIDR) device, respectively. The CIDR was left in place for seven days in all cows. As controls, cows having normal endometrial EGF profiles without peripartum problems and before submission to AI after the last parturition received the EB1 treatment with a CIDR device. Control cows were inseminated (AI) at estrus, and cows that became pregnant by the first AI service were used as fertile controls $(n=5)$. Endometrial samples for EGF assay were collected from all repeat breeder and fertile control cows by repeated biopsy at $0,2,8,16,24$ and $48 \mathrm{~h}$ after the EB injection and on Days 3, 7 and 14 of the estrous cycle initiated after withdrawal of the CIDR device. In Experiment 2 (B), repeat breeder cows having abnormal EGF profiles were treated with 1 or $5 \mathrm{mg}$ of EB (EB1 and EB5 groups, respectively; $\mathrm{n}=30$ for both groups) in combination with a CIDR device and $\mathrm{PGF}_{2 \alpha}$ (25 mg of dinoprost tromethamine). The CIDR device was left in place for seven days in all cows. Repeat breeder cows assigned to the untreated control group $(\mathrm{n}=$ 30) were left untreated for one estrous cycle. The EGF profiles of all cows were examined for the second time, and the cows were then subjected to AI during the next two estrous cycles.

group. In the EB treatment groups, $500 \mu \mathrm{g}$ of cloprostenol was replaced with $25 \mathrm{mg}$ of dinoprost tromethamine (Pronalgon F; Pfizer, Tokyo, Japan) in this experiment. The EGF profiles of the cows were examined a second time without $\mathrm{AI}$ in the estrous cycle initiated after withdrawal of the CIDR device in the EB1 and EB5 groups. The cows were then subjected to AI and diagnosed for pregnancy as described in Experiment 1. The cows in the control group were left untreated for one estrous cycle after initial examination of the endometrial EGF profile, and their EGF profiles were examined in the next estrous cycle. They were then subjected to AI and diagnosed for pregnancy as above.

\section{Data analysis}

In Experiment 1, endometrial EGF concentrations were compared between the treatment groups using a two-way analysis of variance with repeated measurement followed by Fisher's PLSD. In Experiment 2, rates of normalization of endometrial EGF concentrations and pregnancy were compared between the treatment groups with the Fisher's exact test. All analyses were conducted with the Stat View software (ver. 4.5; Abacus Concepts, Berkeley, CA, USA). 


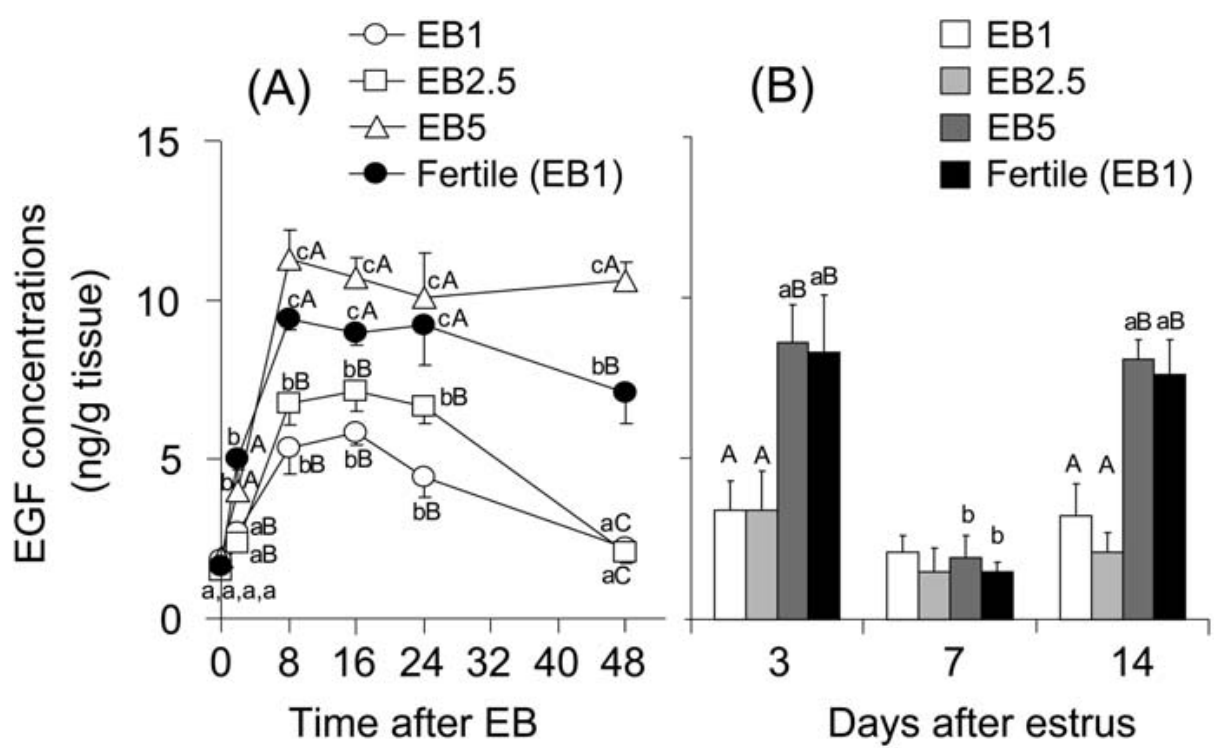

Fig. 2. Endometrial EGF concentrations (mean \pm SEM) after treatments using different doses $(1,2.5$ and 5 $\mathrm{mg}$ ) of estradiol benzoate (EB) with a controlled internal drug release (CIDR) device (EB1, EB2.5 and EB5, respectively; $n=5$ for each group). Fertile control cows $(n=5)$ were given the EB1 treatment. Endometrial samples were collected by biopsy at 0, 2, 8, 16, 24 and $48 \mathrm{~h}$ after the injection of EB (A) and on Days 3, 7 and 14 of the estrous cycle initiated after withdrawal of the CIDR device (B). See Fig. 1 for the treatment schedule. Symbols with different lowercase letters (a, b and c) within the same treatment groups indicate that the values differ between different times $(\mathrm{P}<0.05)$. Symbols with different uppercase letters $(\mathrm{A}, \mathrm{B}$ and $\mathrm{C})$ indicate that the values of the corresponding times differ between the treatment groups $(\mathrm{P}<0.05)$.

\section{Results}

\section{Experiment 1}

In all three EB groups (EB1, EB2.5 and EB5) of repeat breeder cows, the endometrial EGF concentrations at the time of EB injection $(0 \mathrm{~h})$ were similar to those of fertile controls (Fig. 2A). The changes in the EGF concentrations immediately after EB treatment differed between the treatment groups. In the fertile control cows, the EGF concentrations increased within $2 \mathrm{~h}$ after treatment with 1 $\mathrm{mg}$ of EB, showed the highest levels between 8 and $24 \mathrm{~h}$ and then decreased. However, the concentrations were still higher than the pretreatment levels $(0 \mathrm{~h})$ at $48 \mathrm{~h}(\mathrm{P}<0.01)$. In the EB5 group, the endometrial EGF concentrations showed changes similar to the fertile group until $24 \mathrm{~h}$ after EB injection. The EGF concentrations did not decrease after $24 \mathrm{~h}$ but instead remained at the maximal levels until $48 \mathrm{~h}$. The changes in the EGF concentrations in the EB1 and EB2.5 groups were similar to each other. The endometrial EGF concentrations in the two groups were slow to increase, showed lower maximal levels between 8 and 24 h after EB treatment than those of the fertile and EB5 groups $(\mathrm{P}<0.01)$ and returned to the pretreatment levels by $48 \mathrm{~h}$.

The changes in the EGF concentrations during the estrous cycle initiated after CIDR withdrawal also differed between the groups (Fig. 2B). In the EB5 group, the endometrial EGF concentrations on all three days (Days 3, 7 and 14) were within the normal range and were similar to those of the fertile group. In the EB1 and EB2.5 groups, the EGF concentrations showed similar changes to each other. The concentrations of these EB groups on Days 3 and 14 were lower than those of the fertile and EB5 groups and were below the normal range.

\section{Experiment 2}

The proportion of cows having normal endometrial EGF concentrations on all three days after treatment (normalization rate) was greater in the EB5 group than in the other two groups $(\mathrm{P}<0.01$; Table 1). The normalization rate of the EGF profile did not show a significant difference between the EB1 and untreated control groups, although the rate tended to be higher in the EB1 group than in the untreated control group $(\mathrm{P}=0.08)$.

The pregnancy rate was higher in the EB5 group (66.7\%) than in the untreated control (16.7\%) and EB1 groups (40.0\%, $\mathrm{P}<0.05$; Table 1). The pregnancy rate did not differ significantly between the EB1 and control groups, although the rate tended to be higher in the EB1 group than in the untreated control group $(\mathrm{P}=0.08)$. In the EB1 and EB5 groups, the pregnancy rates of the cows with EGF concentrations normalized after treatment (88.9 and 85.0\%, respectively) were greater than those of the cows showing abnormal endometrial EGF profiles (19 and 30\%, respectively, $\mathrm{P}<0.01$; Table 1 ). The pregnancy rates of the cows with normal and abnormal EGF profiles were not different in the control group.

\section{Discussion}

Increases in the endometrial EGF concentrations in repeat 
Table 1. Effect of treatment on the normalization of endometrial EGF concentrations and fertility of repeat breeder cows ${ }^{\mathrm{a}}$

\begin{tabular}{|c|c|c|c|c|c|}
\hline \multirow{3}{*}{$\begin{array}{l}\text { Treatments }^{\mathrm{b}} \\
\text { Untreated control }\end{array}$} & \multirow{2}{*}{\multicolumn{2}{|c|}{$\begin{array}{l}\text { Number (\%) of cows } \\
\text { with the indicated EGF } \\
\text { profile after treatment }{ }^{c}\end{array}$}} & \multicolumn{2}{|c|}{$\begin{array}{l}\text { Number (\%) of pregnant } \\
\text { cows after each insemination }\end{array}$} & \multirow{2}{*}{$\begin{array}{l}\text { Number (\%) } \\
\text { of } \\
\text { pregnant cows }\end{array}$} \\
\hline & & & $1 \mathrm{st}$ & 2nd & \\
\hline & Normal & $4(13.3)^{d}$ & 1 (25.0) & 1 (33.3) & $2(50.0)$ \\
\hline & Abnormal & 26 (86.7) & 1 (3.8) & $2(8.0)$ & 3 (11.5) \\
\hline & Total & 30 & $2(6.7)$ & 3 (10.7) & $5(16.7)^{f}$ \\
\hline \multirow[t]{3}{*}{ EB1 } & Normal & $9(30.0)^{d}$ & 7 (77.8) & $1(50.0)$ & $8 \quad(88.9) * *$ \\
\hline & Abnormal & $21(70.0)$ & $2(9.5)$ & 2 (10.5) & 4 (19.0) \\
\hline & Total & 30 & $9 \quad(30.0)$ & 3 (14.3) & $12(40.0)^{f}$ \\
\hline \multirow[t]{3}{*}{ EB5 } & Normal & $20(66.7)^{\mathrm{e}}$ & $12(60.0)$ & $5(62.5)$ & $17(85.0) * *$ \\
\hline & Abnormal & 10 (33.3) & $0 \quad(0)$ & $3(30.0)$ & $3(30.0)$ \\
\hline & Total & 30 & $12(40.0)$ & 8 (44.4) & $20(66.7)^{g}$ \\
\hline
\end{tabular}

${ }^{a}$ Cows were diagnosed as repeat breeders when they failed to conceive after three AIs without an apparent abnormality in their estrous cycle, reproductive tract or clinical signs. They showed endometrial EGF concentrations outside of the normal range on at least one of the three days (Days 3, 7 and 14) prior to treatment. ${ }^{\mathrm{b}} \mathrm{EB} 1$ and EB5: CIDR programs with 1 or $5 \mathrm{mg}$ of estradiol benzoate (EB), respectively. See Fig. 1B for the treatment schedule. ${ }^{\mathrm{c}}$ Normal: EGF concentrations normalized on Days 3, 7 and 14 of the estrus cycle after treatment. Abnormal: EGF concentrations on at least one of the three days were outside of the normal range. ${ }^{\mathrm{d} \text {, e Values }}$ with different superscripts differ significantly $(\mathrm{P}<0.01)$. ${ }^{\mathrm{f}, \mathrm{g}}$ Values with different superscripts differ significantly $(\mathrm{P}<0.05)$. ${ }^{* *}$ Values are significantly greater than those of the abnormal category within the same group $(\mathrm{P}<0.01)$.

breeder cows after the EB1 and EB2.5 treatments were suppressed compared with the concentrations of the fertile cows given the EB1 treatment. The EGF profiles of the repeat breeder cows given the two treatments failed to return to normal. In contrast, the EB5 treatment produced a similar or even an exaggerated response in the EGF concentration compared with the fertile cows given the EB1 treatment, and the endometrial EGF concentrations normalized in the next estrous cycle. These results indicate that the low endometrial EGF concentrations on Days 3 and 14 of the estrous cycle in repeat breeder cows [11, 22] seem to reflect disruption of endometrial responsiveness to an estrogenic stimulus. At present, the mechanisms causing this suppression are unknown. We are currently investigating expression and localization of estrogen receptors and the integrity of their function to understand the underlying mechanisms of infertility in this type of repeat breeder cow.

Treatment with $5 \mathrm{mg}$ of EB is reported to increase plasma estradiol concentrations to a greater extent and for a longer period than treatments with 1 and $2.5 \mathrm{mg}$ of EB [25, 26]. The difference in the plasma estradiol profile may be responsible for the different changes in the EGF concentrations between the EB5 and other EB treatment groups in the repeat breeder cows. Expression of EGF in the endometrium largely depends on estrogenic action, and the effect of estrogen is enhanced by the presence of progesterone [1, 2]. Thus, EB treatment in combination with a CIDR device during the luteal phase would produce an ideal change in the plasma concentrations of steroid hormones to restore EGF production in the endometrium if sufficient levels of estrogenic action are achieved by use of a high dose of EB. Once high levels of EGF that mimic the peak(s) around Days 3 and/or 14 of the estrous cycle [11] are achieved, cyclic change of EGF production would resume.

The preliminary results in Experiment 1 prompted us to plan a field trial to confirm the effects of the EB5 treatment on restoration of fertility in the repeat breeder cows. The results in Experiment 2 demonstrated high efficacy for the EB5 treatment in restoring fertility. The pregnancy rate after the EB5 treatment (66.7\%) was higher than that of the EB1 treatment (40.0\%), which represents a standard CIDR program that is often chosen as a treatment option for repeat breeder cows in the field. Since the pregnancy rate of the repeat breeder cows that had their EGF concentrations normalized after treatment was high and was similar in both EB groups (88.9 and $85.0 \%$ ), the difference in the pregnancy rate between the two EB groups seems to reflect higher efficiency of the EB5 treatment in normalizing the endometrial EGF profile than seen for the EB1 treatment (66.7\% vs. 30.0\%).

The present study, together with the potential role of EGF in establishment of pregnancy [8-10, 18, 19], suggests that normalization of the EGF profile resulted in normal endometrial function which, in turn, restored fertility in the repeat breeder cows. It would not be reasonable, however, to assume that EGF is the only agent that is affected in the uterine endometria of repeat breeder cows. Alteration of the EGF profile may represent disruption of the endometrial regulatory network, which consists mainly of growth factors and cytokines. The EB5 treatment would have restored not only the EGF profile but also normality in the regulatory network.

There may be other potential mechanisms by which the EB5 treatment produced pregnancy in the repeat breeder cows as discussed previously [22]. A large proportion of pregnancy loss can be attributed to fertilization failure including delayed fertilization, which increases the incidence of early embryonic loss [27]. In repeat breeder cows, the potential for delayed fertilization may be increased by delayed onset of estrus, which has been suggested to be the major deviation in non-fertile cows [28]. Thus, treatment to optimize the timing of $\mathrm{AI}$ including a CIDR program (i.e., the EB1 and EB5 treatments) may produce pregnancy independently of endometrial EGF concentrations in repeat breeder cows. 
Furthermore, some repeat breeder cows may have had subclinical endometritsis, which can be eliminated by the EB5 treatment because high doses (3-5 mg) of EB have been used to treat endometritis in cattle [29]. Although all the repeat breeder cows were examined for histological evidence of endometritis using the endometrial tissues obtained by biopsy in the present study, signs of endometritis could have been missed if the endometritis was restricted to a specific area.

The present results strongly suggest that the EB5 treatment can be recommended as a treatment option for repeat breeder cows losing peaks in their endometrial EGF concentrations during the estrous cycle. However, the duration of CIDR treatment needs to be extended when cows are inseminated during estrus induced by a CIDR treatment because the EB5 treatment with a 7-day CIDR insertion period may cause failure of ovulation after CIDR withdrawal due to insufficient time for follicular development and maturation. In a previous study, two out of eight non-lactating Hereford cows receiving a CIDR with $5 \mathrm{mg}$ of EB and $500 \mu \mathrm{g}$ of cloprostenol with a 7 day interval, similar to the EB5 treatment, failed to ovulate within 7 days after CIDR withdrawal, while all cows given $1 \mathrm{mg}$ of EB ovulated within 6 days [30]. Treatment with $5 \mathrm{mg}$ of EB suppresses FSH for an extended period compared with treatment with low doses $(0.75,1$ and $2.5 \mathrm{mg})$ of EB [25, 26], and follicular wave emergence can be expected to occur later and asynchronously [25, 26, 30]. Consequently, the size of the largest follicles becomes smaller, and some follicles may not acquire the ability to ovulate by the time of the LH surge. In the present study, all cows in the EB5 group, however, showed signs of estrus and ovulated within 5 days after CIDR withdrawal. The conflicting results between the present and previous [30] studies could be attributed to a larger body size and higher metabolic rate of EB in the dairy cows used in our study than the non-lactating beef cattle in the previous study. High feed intake to support a large amount of milk production in high-producing dairy cattle increases liver blood flow and metabolism of progesterone and estradiol [31]. The higher metabolic rate of EB terminates suppression of FSH by EB earlier. Nevertheless, the potential adverse effect of failing to ovulate may exist for the EB5 treatment. It is therefore recommended that the interval between EB and PG treatment be extended to 9-10 days in the EB5 treatment to make up for the delay of follicular wave emergence of 2 to 3 days compared with the EB1 treatment [26, 30].

In conclusion, repeat breeder cows having lesser endometrial EGF concentrations on Days 3 and/or 14 of the estrous cycle may have a suppressed endometrial capacity to produce EGF in response to estrogenic stimuli. A CIDR program with a high dose ( $5 \mathrm{mg}$ ) of EB may reactivate the endometrial capacity to produce EGF and restore cyclic change of endometrial EGF concentrations and fertility.

\section{Acknowledgments}

This study has been supported by grants-in-aid for Scientific Research (No. 11760188, 15580284 and 20580350) from the Japan Society for the Promotion of Science.

\section{References}

1. Brigstock DR. Growth factors in the uterus: steroidal regulation and biological actions. Baillieres Clin Endocrinol Metab 1991; 5: 791-808.

2. Paria BC, Song H, Dey SK. Implantation: molecular basis of embryo-uterine dialogue. Internat J Dev Biol 2001; 45: 597-605.

3. DiAugustine RP, Petrusz P, Bell GI, Brown CF, Korach KS, McLachlan JA, Teng CT. Influence of estrogens on mouse uterine epidermal growth factor precursor protein and messenger ribonucleic acid. Endocrinology 1988; 122: 2355-2363.

4. Huet-Hudson YM, Chakraborty C, De SK, Suzuki Y, Andrews GK, Dey SK. Estrogen regulates the synthesis of epidermal growth factor in mouse uterine epithelial cells. Mol Endocrinol 1990; 4: 510-523.

5. Falck L, Forsberg JG. Immunohistochemical studies on the expression and estrogen dependency of EGF and its receptor and C-fos proto-oncogene in the uterus and vagina of normal and neonatally estrogen-treated mice. Anat Rec 1996; 245: 459-471.

6. Adachi K, Kurachi H, Homma H, Adachi H, Imai T, Sakata M, Higashiguchi O, Yamaguchi M, Morishige K, Sakoyama Y, Miyake A. Estrogen induces epidermal growth factor (EGF) receptor and its ligands in human fallopian tube: involvement of EGF but not transforming growth factor-alpha in estrogen-induced tubal cell growth in vitro. Endocrinology 1995; 136: 2110-2119.

7. Nelson KG, Takahashi T, Bossert NL, Walmer DK, McLachlan JA. Epidermal growth factor replaces estrogen in the stimulation of female genital-tract growth and differentiation. Proc Natl Acad Sci USA 1991; 88: 21-25.

8. Johnson DC, Chatterjee S. Embryo implantation in the rat uterus induced by epidermal growth factor. J Reprod Fertil 1993; 99: 557-559.

9. Threadgill DW, Dlugosz AA, Hansen LA, Tennenbaum T, Lichti U, Yee D, LaMantia C, Mourton T, Herrup K, Harris RC. Targeted disruption of mouse EGF receptor: effect of genetic background on mutant phenotype. Science 1995; 269: 230-234.

10. Sibilia M, Wagner EF. Strain-dependent epithelial defects in mice lacking the EGF receptor. Science 1995; 269: 234-238.

11. Katagiri S, Takahashi Y. Changes in EGF concentrations during estrous cycle in bovine endometrium and their alterations in repeat breeder cows. Theriogenology 2004; 62: 103-112.

12. Kliem A, Tetens F, Klonisch T, Grealy M, Fischer B. Epidermal growth factor receptor and ligands in elongating bovine blastocysts. Mol Reprod Dev 1998; 51: 402-412.

13. Ohtani S, Okuda K, Ohtani M, Yamada J. Immunohistochemically-determined changes in the distribution of insulin-like growth factor-I (IGF-I) and epidermal growth factor (EGF) in the bovine endometrium during the estrous cycle. J Vet Med Sci 1996; 58: 1211-1217.

14. Gharib-Hamrouche N, Chene N, Guillomot M, Martal J. Localization and characterization of EGF/TGF-alpha receptors on peri-implantation trophoblast in sheep. $J$ Reprod Fertil 1993; 98: 385-392.

15. Gharib-Hamrouche N, Chene N, Martal J. Comparative expression of TGF-alpha and EGF genes in the ovine conceptus and uterine endometrium in the peri-implantation period. Reprod Nutri Dev 1995; 35: 291-303.

16. Tamada H, Yoh C, Inaba T, Takano H, Kawate N, Sawada T. Epidermal growth factor (EGF) in the goat uterus: immunohistochemical localization of EGF and EGF receptor and effect of EGF on uterine activity in vivo. Theriogenology 2000; 54: 159-169.

17. Kennedy TG, Brown KD, Vaughan TJ. Expression of the genes for the epidermal growth factor receptor and its ligands in porcine oviduct and endometrium. Biol Reprod 1994; 50: 751-756

18. Zhang Z, Krause M, Davis DL. Epidermal growth factor receptors in porcine endometrium: binding characteristics and the regulation of prostaglandin $\mathrm{E}$ and F2 alpha production. Biol Reprod 1992; 46: 932-936.

19. Bany BM, Kennedy TG. Regulation by epidermal growth factor of prostaglandin production and cyclooxygenase activity in sensitized rat endometrial stromal cells in vitro. J Reprod Fertil 1995; 104: 57-62.

20. Shelton K, Parkinson TJ, Hunter MG, Kelly RW, Lamming GE. Prostaglandin E-2 as a potential luteotrophic agent during early pregnancy in cattle. J Reprod Fertil 1990; 90: $11-17$

21. Asselin E, Bazer FW, Fortier MA. Recombinant ovine and bovine interferons tau regulate prostaglandin production and oxytocin response in cultured bovine endometrial cells. Biol Reprod 1997; 56: 402-408.

22. Katagiri S, Takahashi Y. Potential relationship between normalization of endometrial epidermal growth factor profile and restoration of fertility in repeat breeder cows Anim Reprod Sci 2006; 95: 54-66.

23. Katagiri S, Ho Yuen B, Moon YS. The role for the uterine insulin-like growth factor I in early embryonic loss after superovulation in the rat. Fertil Steril 1996; 65: 426-436.

24. Day ML, Burke CR, Taufa VK, Day AM, Macmillan KL. The strategic use of estradiol to enhance fertility and submission rates of progestin-based estrus synchronization programs in dairy herds. J Anim Sci 2000; 78: 523-529. 
25. O'Rourke M, Diskin MG, Sreenan JM, Roche JF. The effect of dose and route of oestradiol benzoate administration on plasma concentrations of oestradiol and FSH in long-term ovariectomised heifers. Anim Reprod Sci 2000; 59: 1-12.

26. Roche JF, Austin EJ, Ryan M, O'Rourke M, Mihm M, Diskin MG. Regulation of follicle waves to maximize fertility in cattle. J Reprod Fertil 1999; 54 (Suppl): 61-71.

27. Saacke RG, Dalton JC, Nadir S, Nebel RL, Bame JH. Relationship of seminal traits and insemination time to fertilization rate and embryo quality. Anim Reprod Sci 2000; 60-61: 663-677.

28. Erb RE, Gaverick HA, Randel RD, Brown BL, Callahan CJ. Profile of reproductive hormones associated with fertile and non-fertile inseminations of dairy cows. Theriogenology 1976; 5: 227-242.
29. Parkinson TJ. Infertility in the cow: structural and functional abnormalities, management deficiencies and non-specific infections. In: Noakes ED, Parkinson TJ, England GC (eds.), Arthur's Veterinary Reproduction and Obstetrics, $8^{\text {th }}$ ed. London: WB Saunders; 2001: 383-472.

30. Martinez MF, Kastelic JP, Bo GA, Caccia M, Mapletoft RJ. Effects of oestradiol and some of its esters on gonadotrophin release and ovarian follicular dynamics in CIDRtreated beef cattle. Anim Reprod Sci 2005; 86: 37-52.

31. Sangsritavong S, Combs DK, Sartori R, Armentano LE, Wiltbank MC. High feed intake increases liver blood flow and metabolism of progesterone and estradiol-17 $\beta$ in dairy cattle. J Dairy Sci 2002; 85: 2831-2842. 